\title{
The usefulness of routine histological examination of appendicectomy specimens in a South African tertiary centre
}

\author{
O O Jolayemi, ${ }^{1}$ FCS (SA); N B Moodley, ${ }^{2}$ FCS (SA); V Y Kong, ${ }^{2}$ MSc, PhD, MRCS; B Tlou, ${ }^{3}$ PhD; J L Bruce, ${ }^{2}$ FCS (SA); \\ D L Clarke, ${ }^{1,2,4}$ MPhil, MBA, PhD, FCS (SA) \\ ${ }^{1}$ Department of Surgery, Ngwelezane Hospital and Nelson R Mandela School of Medicine, College of Health Sciences, University of KwaZulu- \\ Natal, Durban, South Africa \\ ${ }_{2}^{2}$ Department of Surgery, Pietermaritzburg Hospital Complex and Nelson R Mandela School of Medicine, College of Health Sciences, \\ University of KwaZulu-Natal, Durban, South Africa \\ ${ }^{3}$ Department of Public Health Medicine, School of Nursing and Public Health, College of Health Sciences, University of KwaZulu-Natal, \\ Durban, South Africa \\ ${ }^{4}$ Department of Surgery, Faculty of Health Sciences, University of the Witwatersrand, Johannesburg, South Africa
}

Corresponding author: O O Jolayemi (funsozn@hotmail.com)

\begin{abstract}
Background. It is accepted surgical practice to send all appendicectomy specimens for histological examination, but the usefulness and cost associated with this practice have not been established in our setting, a tertiary hospital in KwaZulu-Natal Province, South Africa (SA). Objectives. To determine the histological diagnoses of appendicectomy specimens in our centre, and the cost of identifying an alternative histological diagnosis requiring further treatment.

Methods. Clinical data on patients undergoing appendicectomy for suspected acute appendicitis during the study period December 2012 August 2015 were retrospectively retrieved from the hybrid electronic medical registry. Histological data were then extracted from the National Health Laboratory Service database. The cost of an appendicitis histology report was sourced from a private laboratory service. Results. A total of 290 patients were identified during the study period. Males had a significantly higher risk $(p<0.0001)$ than females of histologically confirmed appendicitis (odds ratio $3.2,95 \%$ confidence interval $1.7-5.8$ ). The negative appendicectomy rate was $22.4 \%$ (65/290). In 5.9\% of specimens (17/290) an alternative diagnosis was made on histological examination, which influenced the management plan. These were parasitic co-infections in 13 cases (4.5\%), premalignant conditions in 2 and tuberculosis in 2. The average cost of processing each appendicectomy specimen was ZAR871. The cost of identifying each patient with an alternative diagnosis that required treatment was ZAR14 $858([290 \times$ ZAR871]/17).

Conclusions. This audit correlates with other SA studies showing that the aetiological differential for appendicitis is broad. Histological examination therefore remains critical in the management of patients with suspected acute appendicitis in our clinical setting.
\end{abstract}

S Afr Med J 2018;108(4):342-346. DOI:10.7196/SAMJ.2018.v108i4.12759

Acute appendicitis remains one of the most common abdominal surgical emergencies in the world. Incidence rates vary between 8.2 and 15 per 100000 population in South African (SA) studies, and between 52 and 154 per 100000 population in high-income countries (HICs) ${ }^{[1-4]}$ The lifetime risk of developing appendicitis is $8.6 \%$ and $6.7 \%$ in males and females, respectively. ${ }^{[1]}$ Management and therapeutic algorithms must therefore be reviewed on a regular basis to ensure that they are evidence based and cost-effective. One aspect of management is the need for routine histological review. It is accepted surgical practice to send all appendicectomy specimens for histological examination, but the cost of this, especially in lowand middle-income countries (LMICs), is not inconsiderable. ${ }^{[-7]} \mathrm{We}$ therefore set out to review the histopathological findings of patients operated on for suspected acute appendicitis at our tertiary hospital. In addition, we reviewed the clinical and biochemical presentation of our patients and correlated this with the histological findings.

\section{Objective}

To use these data to determine the cost of identifying alternative histological diagnoses requiring further intervention.

\section{Methods}

\section{Clinical setting}

This was a retrospective study undertaken at Grey's Hospital in Pietermaritzburg, SA. The city of Pietermaritzburg is the capital of KwaZulu-Natal Province. The Pietermaritzburg Metropolitan Surgical Service covers the entire western part of the province, with a total catchment population of over 3 million. Our institution serves as the tertiary referral centre for the western part of the province.

Our centre has held and maintained a detailed surgical registry since December 2012. This allows us to capture data on all surgical patients in our service and makes it easy to identify patients operated on for acute appendicitis. The National Health Laboratory Service (NHLS) also has a database that can be searched with individual patient details to retrieve histology results.

The clinical diagnosis of appendicitis was typically made by medical officers with at least 2 years' experience in general surgery. Specialist oversight was reserved for cases where diagnostic or intraoperative difficulty was encountered. Histological assessment was performed by multiple pathologists working at the NHLS and at a private pathology laboratory in Pietermaritzburg. 


\section{Study population}

Clinical data on 290 patients undergoing appendicectomy for suspected acute appendicitis during the study period December 2012 - August 2015 were retrospectively retrieved from the hybrid electronic medical registry. Histological data were then extracted from the NHLS database. The following were excluded from analysis: appendicular masses successfully managed conservatively, incidental appendicectomies, patients with incomplete data, and situations in which appendicectomy was not performed owing to a clear alternative diagnosis in the presence of a macroscopically normal appendix. No patients were subjected to an interval appendicectomy.

\section{Study-specific definitions}

- Acute appendicitis was defined as transmural inflammation or the presence of pus within the lumen of the appendix.

- Periappendicitis was defined as inflammation of the layers of the appendix wall, most commonly the serosa, with sparing of the mucosa.

- Incidental appendicectomy was defined as appendicectomy performed during another procedure where the indication was not acute appendicitis.

- Negative appendicectomy was defined as appendicectomy after which histological examination of the specimen demonstrated periappendicitis, or there was no inflammation, tumour or infectious agent.

Morbidities and mortalities were graded using the Clavien-Dindo classification system (Table 1).

\section{Statistical analysis}

Data including demographic details, clinical symptoms and duration of symptoms, white cell count (WCC), surgical access and intraoperative findings, postoperative complications and histopathological findings were captured using Excel 2016 (Microsoft, USA). Pearson's $\chi^{2}$ test was used to identify variables associated with appendicitis, negative appendicectomy, perforation and morbidity. Statistical significance was considered at $p<0.05$.

\section{Factors predictive of a histological diagnosis of acute appendicitis}

Multivariate analysis was performed to identify clinical factors that can predict the histological finding of acute appendicitis. We constructed receiver operator curves (ROCs) for this. The area under a ROC quantifies the ability of the test to discriminate between individuals with the disease and those without the disease. We constructed plots of the raw and standardised residuals to fully assess the fit of our models.

\section{Cost}

The cash and medical insurance costs of an appendicitis histology report were sourced from a private laboratory service. The average cost was used to estimate the overall cost of our cohort. Based on this, the cost of identifying an alternative diagnosis that required further treatment was calculated.

\section{Ethical considerations}

The surgical registry has class approval (ref. no. UKZN BCA221/13) from the University of KwaZulu-Natal (UKZN) Biomedical Research Ethics Committee (BREC). The protocol for the study was approved by the UKZN BREC (ref. no. BE406/14) and the KwaZulu-Natal Department of Health.

\section{Results}

\section{Demographics and clinical features}

A total of 290 patients were identified during the study period. The male/female ratio was 1.5:1. Demographic and clinical data are set out in Table 2 . The commonest symptom was abdominal pain (98.3\%). Of the 5 patients in whom a history of abdominal pain was not elicited, 2 presented with abdominal distension suggestive of an ileus, 1 gave a poor history due to an altered sensorium, 1 had no clinical details available, and 1 presented with an abdominal mass.

The WCC was elevated in 188 patients, with data on the WCC missing for 27 patients. Surgical access was achieved by midline

\begin{tabular}{ll} 
Table 2. Patient demographics and clinical details $(\mathbf{N}=\mathbf{2 9 0})$ \\
\hline Gender, $n$ (\%) & $172(59.3)$ \\
Male & $118(40.7)$ \\
Female & $23(17-32)$ \\
Age (years), median (IQR) & \\
Symptoms, $n(\%)$ & $285(98.3)$ \\
$\quad$ Pain & $82(28.8)$ \\
Migratory & $79(27.2)$ \\
Anorexia & $190(65.5)$ \\
Nausea and/or vomiting & $3(2-5)$ \\
Duration of symptoms (days), median (IQR) & $12.4(9.6-17)$ \\
White cell count $\left(\times 10^{9} / \mathrm{L}\right)$, median $(\mathrm{IQR})$ &
\end{tabular}

\begin{tabular}{ll} 
Table 1. Clavien-Dindo classification of surgical complications \\
\hline Grade I & $\begin{array}{l}\text { Any deviation from the normal postoperative course without the need for pharmacological treatment or } \\
\text { surgical, endoscopic and radiological interventions. Allowed therapeutic regimens are: drugs as antiemetics, } \\
\text { antipyretics, analgesics, diuretics and electrolytes, and physiotherapy. This grade also includes wound infections } \\
\text { opened at the bedside. } \\
\text { Requiring pharmacological treatment with drugs other than those allowed for grade I complications, also } \\
\text { treatment with blood transfusions and total parenteral nutrition }\end{array}$ \\
Grade II & $\begin{array}{l}\text { Requiring surgical, endoscopic or radiological therapy } \\
\text { Intervention not under general anaesthesia }\end{array}$ \\
Grade III & Intervention under general anaesthesia \\
Grade IIIa & Life-threatening complications, including central nervous system complications, requiring intensive care \\
Grade IIIb & management \\
Grade IV & Single-organ dysfunction (including dialysis) \\
Grade IVa & Multiple-organ dysfunction \\
Grade IVb & Death \\
Grade V &
\end{tabular}


laparotomy in 186 cases (64.1\%), by local incision in $69(23.8 \%)$ and laparoscopically in 33 (11.4\%). Of patients who underwent a local incision, $3(4.3 \%)$ required an extended or 'hockey-stick' incision to complete the procedure. Operative findings are set out in Table 3. Age $\geq 25$ years, duration of symptoms, length of hospital stay, WCC $\geq 10$ $\times 10^{9} / \mathrm{L}$ and morbidity were significantly associated with a perforated appendix. There was a trend towards increased risk of perforation in male patients, but this did not reach statistical significance. Table 4 lists factors associated with perforation.

\section{Histopathological findings}

The histopathological findings are set out in Table 5. Males were three times more likely to have histological appendicitis compared with females (odds ratio 3.2, 95\% confidence interval 1.7 - 5.8) after controlling for age, duration of symptoms and delay in reaching theatre. This finding was statistically significant $(p<0.0001)$. The negative appendicectomy rate (NAR) was $22.4 \%$ (65/290, 26 males and 39 females). The NAR in the female cohort was significantly higher than that for males $(p=0.0003)$. The median age of patients who underwent negative appendicectomy was 25 years (interquartile range (IQR) 18 - 32).

Of 7 appendicectomy specimens that appeared macroscopically normal, 1 (14.3\%) had histological evidence of inflammation. However, in 38 (13.4\%) of the specimens with macroscopic evidence of inflammation, histological analysis revealed no pathology of the

Table 3. Operative details and histopathological findings $(N=290)$

\begin{tabular}{ll}
\hline & $\boldsymbol{n}(\mathbf{\%})$ \\
\hline Normal appendix & $7(2.4)$ \\
Acutely inflamed & $102(35.2)$ \\
Gangrenous & $2(0.7)$ \\
Perforated & $179(61.7)$ \\
Localised contamination & $49(27.3)$ \\
Periappendiceal phlegmon/abscess & $47(26.3)$ \\
Generalised peritonitis & $83(46.4)$
\end{tabular}

Table 4. Factors associated with perforation $(N=290)$

\begin{tabular}{llll}
\hline & $\begin{array}{l}\text { Patients in } \\
\text { study, } \boldsymbol{n}(\%)\end{array}$ & $\begin{array}{l}\text { Perforation, } \\
\boldsymbol{n}(\%)\end{array}$ & $\boldsymbol{p}$-value \\
\hline Age $\geq 25$ years & $124(42.8)$ & $81(65.3)$ & 0.02 \\
$\begin{array}{l}\text { Male gender } \\
\text { Duration of }\end{array}$ & $172(59.3)$ & $116(67.4)$ & 0.7 \\
$\begin{array}{l}\text { symptoms }>3 \text { days } \\
\text { Length of hospital }\end{array}$ & $122(42.1)$ & $92(75.4)$ & 0.0001 \\
$\begin{array}{l}\text { stay }>4 \text { days } \\
\text { White cell count }\end{array}$ & $188(64.8)$ & $124(66.0)$ & 0.04 \\
$\geq 10 \times 10^{9} / \mathrm{L}$ & & & \\
Morbidity & $131(45.2)$ & $120(91.6)$ & $<0.00001$
\end{tabular}

\section{Table 5. Histopathological findings $(N=290)$}

\begin{tabular}{ll}
\hline & $\boldsymbol{n}(\%)$ \\
\hline Normal & $44(15.2)$ \\
Periappendicitis & $21(7.2)$ \\
Appendicitis & $223(76.9)$ \\
Parasites & $13(5.8)$ \\
Granulomatous inflammation & $1(0.4)$ \\
Mycobacterium tuberculosis & $2(0.7)$ \\
Neoplasia & $2(0.7)$
\end{tabular}

appendix. Of the patients without histological evidence of inflammation, $9(13.8 \%)$ had faecoliths, $4(6.2 \%)$ pelvic inflammatory disease, $3(4.6 \%)$ fibrous obliteration of the appendiceal lumen, $1(2.3 \%)$ an ovarian cyst and 1 (2.3\%) intestinal tuberculosis (confirmed by polymerase chain reaction testing), which resulted in caecal perforation.

A total of 21 patients met the criteria for periappendicitis. The median age was 23 years (IQR 20 - 32). A cause for the periappendicitis was only identified in 2 of the 21 (9.5\%), both cases being due to pelvic inflammatory disease. In the group with appendicitis, parasites were identified in 13 cases (5.8\%). Eleven of these patients (84.6\%) had schistosomiasis, and there was 1 infestation with Enterobius vermicularis (7.7\%) and 1 with Trichuris trichiura $(7.7 \%)$. Nine patients in the schistosomiasis group had a perforated appendix, with a perforation rate of $81.8 \%$.

Premalignant conditions were identified in 2 patients $(0.7 \%)$. The first was a 79-year-old man with low-grade mucinous cystadenoma. Appendicectomy was completed laparoscopically in this case. The second patient was a 34-year-old woman with mucinous mucosal hyperplasia who underwent laparotomy. She presented with signs and symptoms suggestive of a perforated appendix. Histological examination confirmed appendicitis in addition to the neoplasm. No case of carcinoid disease of the appendix was identified.

\section{Factors predictive of a histological diagnosis of appendicitis}

Of the clinical factors age, gender, duration of symptoms and time to operation, only male gender was associated with an increased likelihood of a histological diagnosis of acute appendicitis. The WCC was not a good predictor for the histological diagnosis of acute appendicitis. For histological appendicitis, the area under the curve was 0.621 for WCC and the sensitivity, specificity, and positive and negative predictive values were $71.4 \%, 28.3 \%, 71.1 \%$ and $22.7 \%$, respectively. Residual analysis met the linearity, normality and homogeneity of variance assumptions of logistic regression. The Hosmer-Lemeshow test had a $p$-value $>0.05$ and the points along the scatterplots were symmetrical both above and below a straight line, with observations being equally spaced out along the line, assuming linearity.

\section{Morbidity and mortality}

The morbidities and mortality using the Clavien-Dindo classification are set out in Table 6. The overall morbidity rate was $45.2 \%$ (131/290). Surgical site infection (7.9\%), nosocomial pneumonia (5.9\%), prolonged ileus $(2.4 \%)$ and acute kidney injury $(2.4 \%)$ were the most frequent morbidities. Of the patients with surgical site infection, 4 (17.4\%) had dehiscence of the sheath, and 2 (50.0\%) of these went on to develop enteroatmospheric fistulas. Three of the patients

\begin{tabular}{|c|c|}
\hline Clavien-Dindo grade & $n(\%)$ \\
\hline I & $35(12.1)$ \\
\hline II & $36(12.4)$ \\
\hline \multicolumn{2}{|l|}{ III } \\
\hline IIIa & $2(0.7)$ \\
\hline IIIb & $34(11.7)$ \\
\hline \multicolumn{2}{|l|}{ IV } \\
\hline IVa & $19(6.6)$ \\
\hline $\mathrm{IVb}$ & $1(0.3)$ \\
\hline V & $4(1.4)$ \\
\hline
\end{tabular}




\section{Table 7. The KwaZulu-Natal experience of acute appendicitis}

\begin{tabular}{llll}
\hline & $\begin{array}{l}\text { Prince Mshiyeni } \\
\text { Hospital (2009) })^{[10]}\end{array}$ & $\begin{array}{l}\text { Pietermaritzburg } \\
(\mathbf{2 0 1 2})^{[2]}\end{array}$ & $\begin{array}{l}\text { Pietermaritzburg (2017, } \\
\text { the present study) }\end{array}$ \\
\hline Delay in presentation (days), mean & 4 & 3.7 & 5 \\
Perforation (\%) & 30.5 & 57 & 61.7 \\
NAR (\%) & 17 & 10 & 22 \\
Unusual histological findings (\%) & 8.6 & Not available & 5.9 \\
Overall morbidity (\%) & 42.8 & Not available & 45.2 \\
Mortality (\%) & 1.2 & 2 & 1.4 \\
NAR = negative appendicectomy rate. & & &
\end{tabular}

with acute kidney injury required dialysis. There were 4 cases of incomplete appendicectomy (1.4\%). One of these patients presented with surgical site infection and a hernia over a local incision made 9 months previously for appendicectomy. Five ileostomies were reported in this cohort; 1 patient had a persistently high output, and another underwent successful reversal of the ileostomy during the same admission.

One patient was left with a ventral hernia, which was repaired within 12 months of the index operation. The only major morbidity in the group of patients undergoing laparoscopic appendicectomy was in a patient who presented 4 days after the procedure with strangulated port-site herniation requiring laparotomy. A total of 24 patients (8.3\%) required intensive care unit (ICU) admission and organ support, 5 (20.8\%) of whom required support for more than one organ system. The median length of hospital stay was 4 days (IQR 2 - 6), and the mortality rate was 1.4\% (4/290). All the patients who died had intraoperative evidence of perforation and required ICU admission upfront.

\section{Cost}

The average cost of processing each appendicectomy specimen was ZAR871. The histological result influenced the management plan in 17 of the 290 patients. The cost of identifying each patient with unusual histological findings requiring further intervention was ZAR14 $858([290 \times$ R871]/17) .

\section{Discussion}

This retrospective review demonstrated a broad aetiological differential for patients with appendicitis. Pain remains the commonest presenting symptom. The perforation rate was high, and perforation was associated with a raised WCC, an increased length of hospital stay and increased morbidity. The cost of detecting one patient requiring further intervention in the form of medical therapy, oncological resection and/or surveillance was $\sim$ ZAR15 000 .

This study confirms previous work from SA and our institution showing that acute appendicitis often presents at an advanced stage and is associated with significant morbidity and mortality. ${ }^{[2,8-11]}$ Appendicitis in our setting is almost exclusively associated with complicated disease and diffuse intra-abdominal sepsis. Table 7 compares the findings of the different studies done in KwaZulu-Natal over the past two decades.

Acute appendicitis is usually caused by luminal obstruction secondary to intraluminal faecoliths and fibrous obliteration, which results in progressive ischaemia of the appendix wall. Other causes of acute appendicitis, which may only be diagnosed on histological examination, include inflammatory bowel disease, primary and secondary neoplastic conditions, and infectious agents such as parasites, Mycobacterium tuberculosis and Yersinia. ${ }^{[12]}$ Data from this study confirm the broad list of aetiological differentials in patients with appendicitis. These included infectious diseases and premalignant conditions that were not suspected intraoperatively. A local study by Chamisa ${ }^{[10]}$ showed a similar rate of alternative histological diagnoses, but Jones et al. ${ }^{[6]}$ and Chandrasegaram et al. ${ }^{[13]}$ from HICs reported lower rates of $1.96 \%$ and $2.8 \%$, respectively.

With the low rates of alternative histological diagnoses in HICs, the necessity for routine histological examination of appendicectomy specimens is increasingly being questioned owing to the associated cost. ${ }^{[-7]}$ In addition to the cost, those opposed to routine histological examination cite the growing body of evidence in support of non-operative management of appendicitis. ${ }^{[1,15]}$ Protagonists argue that because of the poor correlation between intraoperative and histological findings, selective histological assessment would miss patients with a diagnosis other than benign appendicitis, ${ }^{[6,7,12]}$ as shown in our study.

\section{Study limitations}

The study was limited by its small size and missing data as a result of the retrospective design. In addition, cost-effectiveness of routine histopathological assessment could not be determined owing to the study design and lack of follow-up data. Further studies to explore the cost-effectiveness of routine histological analysis are required.

\section{Conclusions}

This audit correlates with other studies from SA demonstrating that patients with acute appendicitis present with advanced disease and increased morbidity. While the utility of routine histological assessment is questioned in HICs, it remains important in LMICs owing to the more extensive aetiological differential.

\section{Acknowledgements. None.}

Author contributions: OOJ: conception and design, writing of manuscript and analysis of data; NBM and VYK: critical review of manuscript; BT: statistical analysis; JLB: data capture and management; DLC: conception and design and critical review of manuscript.

Funding. None.

Conflicts of interest. None.

1. Walker AR, Walker BF, Manetsi B, Tsotetsi NG, Segal I. Appendicitis in Soweto, South Africa: Traditional healers and hospitalization. J R Soc Health 1989;109(6):190-192. https://doi. org/10.1177/146642408910900604

2. Kong VY, Bulajic B, Allorto NL, Handley J, Clarke DL. Acute appendicitis in a developing country. World J Surg 2012;36(9):2068-2073. https://doi.org/10.1007//00268-012-1626-9

3. Addiss DG, Shaffer N, Fowler BS, Tauxe RV. The epidemiology of appendicitis and appendectomy in the United States. Am J Epidemiol 1990;132(5):910-925. https://doi.org/10.1093/oxfordjournals.aje. in the United States. Am J Epidemiol 1990;132(5):910-925. https://doi.org/10.1093/oxfordjournals.aje. al15734

4. Andersson R, Hugander A, Thulin A, Nystrom PO, Olaison G. Indications for operation in suspected appendicitis and incidence of perforation. BMJ 1994;308(6921):107-110. https://doi.org/10.1136/ bmj.308.6921.107

Healy DA, Aziz A, Wong M, et al. A descriptive cost analysis study of cases of right iliac fossa pain. Int J Surg 2013;11(7):524-528. https://doi.org/10.1016/j.ijsu.2013.05.001

6. Jones AE, Phillips AW, Jarvais JR, Sargen K. The value of routine histopathological examination of appendicectomy specimens. BMC Surg 2007;7:17. https://doi.org/10.1186/1471-2482-7-17

. Swank H, Eshuis E, Ubbink D, Bemelman W. Is routine histopathological examination of appendectomy specimens useful? A systematic review of the literature. Colorec Dis 2011;13(11):12141221. https://doi.org/10.1111/j.1463-1318.2010.02457.x 
8. Kong VY, Sartorius B, Clarke DL. Acute appendicitis in the developed world is a morbid disease. Ann R Coll Surg Engl 2015;97(5):390-395. https://doi.org/10.1308/003588415x14181254790608

9. Levy RD, Degiannis E, Kantarovsky A, Maberti PM, Wells M, Hatzitheofilou C. Audit of acute appendicitis in a black South African population. S Afr J Surg 1997;35(4):198-202

10. Chamisa I. A clinicopathological review of 324 appendices removed for acute appendicitis in Durban,

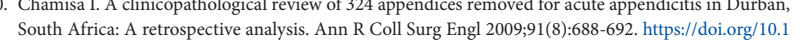
South Africa: A retrospective analysis. Ann R Coll Surg Engl 2009;91(8):688-692. https://doi.org/10.1
308/003588409x12486167521677

11. Madiba TE, Haffejee AA, Mbete DL, Chaithram H, John J. Appendicitis among African patients at
King Edward VII Hospital, Durban, South Africa: A review. East Afr Med J 1998;75(2):81-84. King Edward VIII Hospital, Durban, South Africa: A review. East Afr Med J 1998;75(2):81-84.

12. Akbulut $\mathrm{S}$, Tas $\mathrm{M}$, Sogutcu $\mathrm{N}$, et al. Unusual histopathological findings in appendectomy specimens: A retrospective analysis and literature review. World J Gastroenterol 2011;17(15):1961-1970. https:// doi.org/10.3748/wjg.v17.i15.1961

13. Chandrasegaram MD, Rothwel LA, An EI, Miller RJ. Pathologies of the appendix: A 10-year review of 4670 appendicectomy specimens. Aust N Z J Surg 2012;82(11):844-847. https://doi.org/10.1111/ j.1445-2197.2012.06185.x
14. Varadhan K, Neal K, Lobo D. Safety and efficacy of antibiotics compared with appendicectomy for treatment of uncomplicated acute appendicitis: Meta-analysis of randomized controlled trials. BM] 2012;344:e2156. https://doi.org/10.1136/bmj.e2156

15. Tugnoli G, Giorgini E, Biscardi A, et al. The NOTA study: Non-operative treatment for acute appendicitis: Prospective study on the efficacy and safety of antibiotic treatment (amoxicillin and clavulanic acid) in patients with right sided lower abdominal pain. BMJ Open 2011;1:e000006. https:/ doi.org/10.1136/bmjopen-2010-000006

Accepted 18 October 2017. 